\title{
Management of Drought Stress to Improve Field Screening of Peanuts for Resistance to A spergillus flavus
}

\author{
V. K. Mehan. R. C. Nageswara Rao, D. McDonald, and J. H. Williams
}

Groundnut Pathology (first and third authors) and Groundnut Physiology (second and fourth authors) Units, Legumes Program, International Crops Research Institute for the Semi-Arid Tropics (ICRISAT), Patancheru P.O. 502 324, A.P., India.

ICRISAT Journal Article JA 698.

Accepted for publication 20 November 1987 (submitted for electronic processing).

\section{ABSTRACT}

Mehan. V. K.. Rao. R. C. N. McDonaid, D.. and Williams, J. H. 1988. Manugement of drought stress to improve field screening of peanuts for resistance to Aspergillus navus. Phytopathology 78:659-663.

Drought stress during late stages of pod maturation in an irrigated peanut crop during the post rainy season significantly increased the amount of seed infection by Aspergillus flavus. A line-souree sprinkler irrigation system imposing a drought-stress gradient was used for field screening of peanut genotypes for resistance to seed infection by $A$. flavus. A significant. positive. linear relationship was found between water deficit (drough intensity) and seed infection in peanut genotypes. Cienotypic differences for seed infection by $A$. Mavus were evident at all levels of drought-stress, but under the more severe drought stress conditions, the genotypes resintant to A. flavus had low but positive levels of seed infection giving improved statistical precision.

Additional key word: aflatoxins.

The toxigenic fungus Aspergillus flavus Link ex Fries can infect peanuts (Arochis hypogaea L.) and contaminate seeds with aflatoxins either before or after the crop is harvested (5). Drought stress during the last 4-6 wk of crop development has been found to favor invasion of pods and seeds by $A$. flavus $(2.8,14,15)$. Drought is usually associated with elevated pod-zone soil temperatures, and high soil temperature may also influence the production of aflatoxins in seeds infected by $A$. flavus (2). Most reports of preharvest contamination of peanuts with aflatoxins have been

C 1988 The American Phytopathological Society from areas where crops have been subjected to drought $(1,4,6,10,12,13)$, and particularly from the semi-arid tropics where drought is of common occurrence. There is only a single report on the use of drought stress to field-screen peanut genotypes for resistance to aflatoxin contamination (3). Evaluation of peanut genotypes for resistance to seed infection by $A$. flavus in the field has generally been done on rainy season crops, which may or may not suffer from drought during pod development $(3,4,12,16)$. In locations such as ICR ISAT Center, where peanuts can be grown as an irrigated dry season crop, it is possible to screen genotypes for field resistance to seed invasion by $A$. flavus under imposed lateseason drought stress. 
This paper reports the effects of water deficit on seed infection of some peanut genotypes by $A$. flevus and considers how management of drought-stress can be used to improve screening of peanuts for resistance to $\mathrm{A}$. Mlovus.

\section{MATERIALS AND METHODS}

All experiments were conducted at ICRISAT Center. Patancheru $\left(17^{\circ} 3^{\prime} N, 78^{\circ} 16^{\prime} \mathrm{E}\right)$, near Hyderabad. India. The crops were grown during the postrainy season (November-April) on Alfisols with water holding capacity of about $100 \mathrm{~mm}$ in $120 \mathrm{~cm}$ profile. In all experiments, $40 \mathrm{~kg} \mathrm{ha}^{-1}$ of $\mathrm{P}_{2} \mathrm{O}_{\text {, were applied at land }}$ preparation.

Eflects of timains of droustht uress on preharveat seed infection by A. Movws. During the 1984-1985 postrainy season. eight genotypes were grown in a split-plot design with three replications. The main-plots were assigned to drought treatments and subplots to genotypes. These genotypes included four resistant (Ah 7223. J 11, UF 71513, and PI 337394F) and four susceptible (TMV 2. Gangapuri, EC 76446 [292], and NC Ac 17090) to in vitro seed colonization by $A$. Javus of rehydrated, mature, stored seed (11,12). Plots were $9 \mathrm{~m}$ long by $3.75 \mathrm{~m}$ wide. Seeds were sown singly at $10-\mathrm{cm}$ spacing along $75-\mathrm{cm}$ wide ridges. All plots were furrowirrigated to field capacity (at 7-day intervals) until 85 days after sowing. Three drought-stress treatments were then imposed by withholding irrigation from 85-115, 85-125, or 95-125 days after sowing. Plots that were drought-stressed from 85-115 days after nowing were then irriguted. Control plots were irrigated to field capacity at 7-day intervals throughout the growing period. Al plots were harvested at 125 days after sowing. At harvest. 25-30 plants were relected at random from each plot, and about 500 mature, undamaged pods were collected from them. The pods were hand-shelled, and 200 weeds from each plot were examined for infection by $A$. Mavus (12). The seeds were surface-sterilized by soaking for $3 \mathrm{~min}$ in $0.1 \%$ aqueous solution of mercuric chloride. rinsed in two changew of aterile distilled water, and then plated onto Crapek-Dox agar medium with rose bengal and streptomycin in petri plates for isolation of fungi. The plates were incu. bated at $25 \mathrm{C}$ in the durk and colonies of fungi growing from seeds were recorded after $5-7$ days. No distinction was made bet ween colonies of $A$. Novus and A. parasiticus Speare, both being referred to as $A$. flavus in this paper. From many earlier experiments it was estimated that more than $90 \%$ of Aspergillus flavus group fungi isolated from peanut seeds and from peanut fields at ICRISAT Center were A. flavus.

Another trial was conducted in the same season with the same eight genotypes. In this trial, drought-stress (imposed by withholding irrigation from 95-125 days after sowing) was compared with full irrigation (plots irrigated to field capacity at 7-day intervals throughout the growing period). The genotypes were harvested 125 days after sowing, and pods sampled for seed infection by $A$. navus as described above. This trial was repeated during the 1985-1986 postrainy season.

Efiects of intenalty of drought on seed infection by A. flovus (1983-1984 and 1985-1986 poitralny seasona). Seventeen peanut genotypes were tested for resistance/ susceptibility to seed infection by A. Ravus under different drought intensities. Six genotypes (Ah 7223. J II, U 4-47-7, Var, 27, Faizpur, and C 55-437) were resistant to in vitro seed colonization by A. Mavus, 10 (Exotic-6, NG 387 , GFA Spanish. Sir of Bizapur, 26-5-2, Local-3, TMV 2, Gangapuri, EC 76446[292], and Robut 33-1) were susceptible. and one (U 1-2-1) was highly susceptible.

The layout of the experiment was similar in both years and is outlined in Figure 1. The genotypes were each sown in two rows across 10 beds ( $1.2 \mathrm{~m}$ width), the rows being $30 \mathrm{~cm}$ apart. and seeds were sown singly at $10-\mathrm{cm}$ spacing along the rows. There were three replications. All plots were irrigated to field capacity at 7-day intervals up to 95 days after sowing. using sprinklers. Then a line-source sprinkler irrigation system (7) was used to create a gradient of water deficit from beds 1 to 10 . thus simulating drough stress of increasing intensity. Bed I was near the sprinkler line and received about $50 \mathrm{~mm}$ of water for ench irrimation, while bed 10 was
$12 \mathrm{~m}$ from the sprinkler line and received only $2 \mathrm{~mm}$. The exact amounts of water applied were determined at each irrigation using catchcans placed perpendicularly to the sprinkler line at three locations in each of the 10 beds. During the treatment period (95-125 days after sowing). five sprinkler irrigations were applied at weekly intervals, and the cumulative amounts of water received by each bed over this period were determined. The drought intensity was expressed in terms of percentage water deficit which was calculated by the formula :

$$
y=\left[\left(X_{1}-x_{2}\right) / x_{1}\right] \cdot 100
$$

where $Y$ is the percent water deficit. $X_{1}$ is cumulative evaporation measured during drought treatment, and $X_{2}$ is cumulative amount of water applied during the drought treatment. The data on daily cumulative evaporation were collected from a class $A$ open pan situated in the ICRISAT Meteorological Laboratory, about $1 \mathrm{~km}$ from the experimental site. Water applied and consequent water deficit created in different beds during the drought treatment period are given in Table 1.

Soil temperatures in the pod zone were recorded by thermocouples placed at $5-\mathrm{cm}$ depth at four locations in beds 2,4 . 6,8 , and 10. Spot values were recorded at 0600 and 1400 hours on alternate days starting from 95 days after sowing.

Plants were harvested at 125 days after sowing and arranged in windrows with pods exposed to dry for 2 days. Mature pods were picked from the plants and sun-dried to a seed moisture content of $7-8 \%$. One'hundred seed from the dried pods from the second, fourth, sixth, eighth, and tenth beds, in each replication, were tested as described above for infection by $A$. Javus.

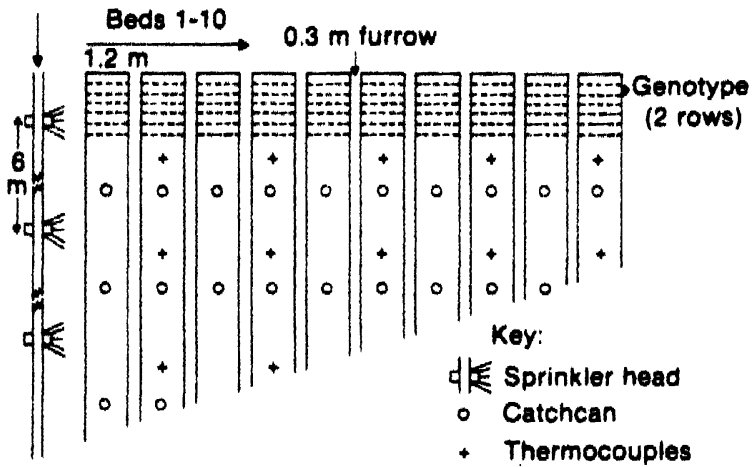

Fig. 1. The line-source sprinkler irrigation system and field arrangement of genotypes, sprinklers. culchcans, and thermocouples used to establish a gradient of water deficiency across the experiment unit.

TABL.E 1. Amount of water applied and water deficit created in different beds using the line-source sprinkter irrigation system during the 1983-1984 and 1985-1986 postrainy seasons

\begin{tabular}{|c|c|c|c|c|}
\hline \multirow[b]{2}{*}{ Bed no. } & \multicolumn{2}{|c|}{$1983-1984$} & \multicolumn{2}{|c|}{$1985-1986$} \\
\hline & $\begin{array}{l}\text { Amount of } \\
\text { witer applied } \\
\text { (cm) }\end{array}$ & $\begin{array}{c}\text { Water } \\
\text { deficit } \\
\left(C_{C}\right)\end{array}$ & $\begin{array}{l}\text { Amount of } \\
\text { water applied } \\
(\mathrm{cm})\end{array}$ & $\begin{array}{l}\text { Water } \\
\text { deficit } \\
(S)\end{array}$ \\
\hline $\begin{array}{c}1 \\
2 \\
3 \\
4 \\
5 \\
6 \\
7 \\
8 \\
9 \\
10\end{array}$ & $\begin{array}{r}20.8 \\
18.7 \\
16.5 \\
13.6 \\
10.3 \\
6.9 \\
3.7 \\
1.1 \\
0.8 \\
0.2\end{array}$ & $\begin{array}{l}42 \\
48 \\
54 \\
62 \\
71 \\
80 \\
90 \\
96 \\
98 \\
99\end{array}$ & $\begin{array}{l}18.5 \\
17.7 \\
16.4 \\
15.0 \\
11.8 \\
7.4 \\
3.3 \\
1.1 \\
0.3 \\
\ldots\end{array}$ & $\begin{array}{l}33 \\
36 \\
41 \\
46 \\
58 \\
73 \\
88 \\
96 \\
99 \\
100\end{array}$ \\
\hline
\end{tabular}

Cumulative amount of water applied during the treatment period $195-125$ days after sowing). 
Statiatical andycis. In the experiment on timing of drought. analyses of variance were performed for percent seed infection by A. flavus, using are sine transformed values. In the experiment where drought intensity was varied under line-source irrigation. analyses of variance for seed infection by $A$. flavus were done separately over genotypes for beds 2, 4, 6, 8. and 10. For each genotype. the mean values for seed infection by $A$. flavus in each of these beds were regressed against the respective percent water deficits.

\section{RESULTS}

Effects of timing of drought streas. Drought treatments increased seed infection by $A$. flavus (Table 2) but did not differ significantly from one another. Significant genotypic differences were found for seed infection by $A$. flavus in both fully irrigated and drought-stress treatments: genotypes with resistance to in vitro seed colonization by A. flavus (Ah 7223. J 11 , and UF 71513) had significantly lower percentages of seed infected than had the susceptible genotypes (TMV 2, Gangapuri. EC 76446[292], and NC Ac 17090). Significant interactions $(P<0.045)$ were found between genotypes and drought-stress treatments for seed infection by $A$. flavus.

In the other trials (1984-1985 and 1985-1986 seasons), lateseason drought-stress (from 95-125 days after sowing) significantly increased infection by A. Mavus in seeds of all eight

TABI E 2. Seed inkection by Aspergillus flavus in eight peanut genotypes grown under irrigated and drought-stressed treatments in the 1984- 1985 postrainy season

\begin{tabular}{|c|c|c|c|c|}
\hline \multirow[b]{3}{*}{ Genotypes } & \multicolumn{4}{|c|}{ Seed infected by $A$. favus (fi) } \\
\hline & \multirow{2}{*}{$\begin{array}{l}\text { Full } \\
\text { irrigation" }\end{array}$} & \multicolumn{3}{|c|}{ Perind of drought stress (I)AS) ${ }^{n}$} \\
\hline & & $85-115$ & $85-125$ & $95-125$ \\
\hline Ah 7223 & $0.1(1.9)^{\prime}$ & $1.0(5.7)$ & $0.6(4.6)$ & $0.2(2,7)$ \\
\hline J11 & $0.1(1.9)$ & $0.4(3.8)$ & $1.9(7.9)$ & $1.3(6.5)$ \\
\hline$(1 F 71513$ & $0.4(3.8)$ & $0.4(3.8)$ & $0.9(5.4)$ & $1.6(7.3)$ \\
\hline PI 337394F & $0.4(3.8)$ & $1.9(7.9)$ & $2.3(8.7)$ & $3,3(10.4)$ \\
\hline TMV 2 & 1.917 .91 & $4.3(12.0)$ & $3.6(11.1)$ & $7,0\{15.3\}$ \\
\hline Gangapuri & $2.3(8.7)$ & $5.0(12.9)$ & $7.2(15.5)$ & $1.3 .3(21.4)$ \\
\hline NC AC 17090 & $1.3(6.5)$ & $4.0(11.5)$ & $8.1(16.5)$ & $6.3(14.6)$ \\
\hline EC 76446(292) & $4.0(11.5)$ & $10.7(19.1)$ & $14.2(22.5)$ & $13.2(21.3)$ \\
\hline
\end{tabular}

Full irrigation at 7-day intervals was to field capacity throughout the growing season.

"DAS = Days after sowing

Values in parentheses are arc sine transformations. The standard error for the experiment was \pm 1.6 with a coefficient of variation of $27.9 \%$

TABLE 3, Seed infection by Aspergillus favus in eight pea nut genotypes grown under full irrigation and with a 30-day drought period in the 1984-1985 and 1985-1986 postrainy seasons

\begin{tabular}{|c|c|c|c|c|}
\hline \multirow[b]{3}{*}{ Genotypes } & \multicolumn{4}{|c|}{ Seed infected by $A$. flavus (\%) } \\
\hline & \multicolumn{2}{|c|}{$1984-1985$} & \multicolumn{2}{|c|}{$1985-1986$} \\
\hline & Irrigation" & $\frac{\text { Drought }}{(95-125 \text { DAS)" }}$ & Irrigation & $\begin{array}{c}\text { Drought } \\
\text { (95-125 DAS) }\end{array}$ \\
\hline $\begin{array}{l}\text { Ah } 7223 \\
\text { J II } \\
\text { UF } 71513 \\
\text { PI 337394F } \\
\text { TMV 2 } \\
\text { Gangapuri } \\
\text { NCAC 17090 } \\
\text { EC 76446(292) }\end{array}$ & $\begin{array}{l}0.4(2.5)^{\prime} \\
0.7(3.1) \\
0.7(3.4) \\
1.2(6.3) \\
2.9(9.5) \\
4.6(12.3) \\
2.4(8.6) \\
5.8(13.5)\end{array}$ & $\begin{array}{l}1.4(6.8) \\
2.0(8.0) \\
2.3(8.4) \\
3.4(10.6) \\
6.6(14.6) \\
12.8(20.8) \\
14.2(21.9) \\
13.7(20.8)\end{array}$ & $\begin{array}{l}0.0(0.0) \\
0.0(0.0) \\
0.0(0.0) \\
0.5(3.3) \\
1.0(5.6) \\
3.0(9.9) \\
4.5(12.2) \\
3.7(11.0)\end{array}$ & $\begin{array}{l}0.8(5.2) \\
1.0(5.7) \\
1.216 .2) \\
1.7(7.3) \\
3.7(11.0) \\
9.5(17.9) \\
13.3(21.4) \\
16.7(24.1)\end{array}$ \\
\hline
\end{tabular}

'Full irrigation at 7-day intervals was to field capacity throughout the growing season.

"DAS = Days after sowing.

"Values in parentheses are arc sine transt ormations. The standard error for the 1984-1985 experimem was \pm 0.91 with a coefficient of variation of 25. $4 \%$ for 1985-1986 experiment it was \pm 0.43 with a coefficient of variation of $8.5 \%$. genotypes tested (Tuble 3). levels of infection being of a similar order to those recorded in the first trial (Tables 2 and 3). Significant differences in seed infection by A. flavus were aga in found between genotypes. In both seasons, the genotype $X$ drought-stress interactions were highly significant $(P<0.001)$ for seed infection by $A$. Navus.

Effects of intendity of late-season drought streas. The line-source irrigation created a water deficit gradient and an associated mean pod-zone soil temperature gradient ranging from 21.2-24.1 C (minimum) to 29.2-40.1 C (maximum) from beds 2 to 10. In general, seed infection of a genotype by $A$. flavus increased with increasing water deficit in both seasons (Figs. 2 and 3). There were

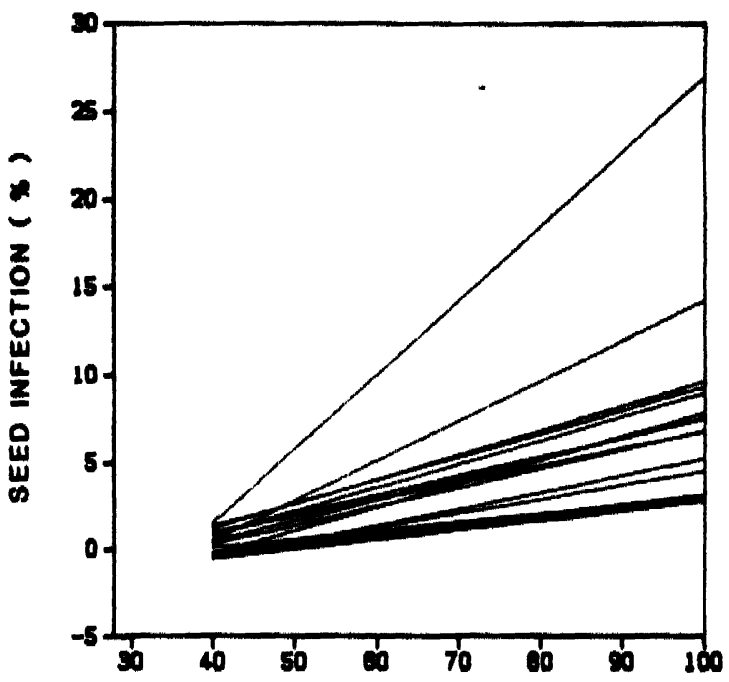

WATER DEFICIT ( $\%$ )

Fig. 2. Relationship between water deficit and seed infection by Aspergillus Mavus in 17 peanut genotypes during the 1983-1984 postrainy season (All regression lines are significant at $p<0.05$ )

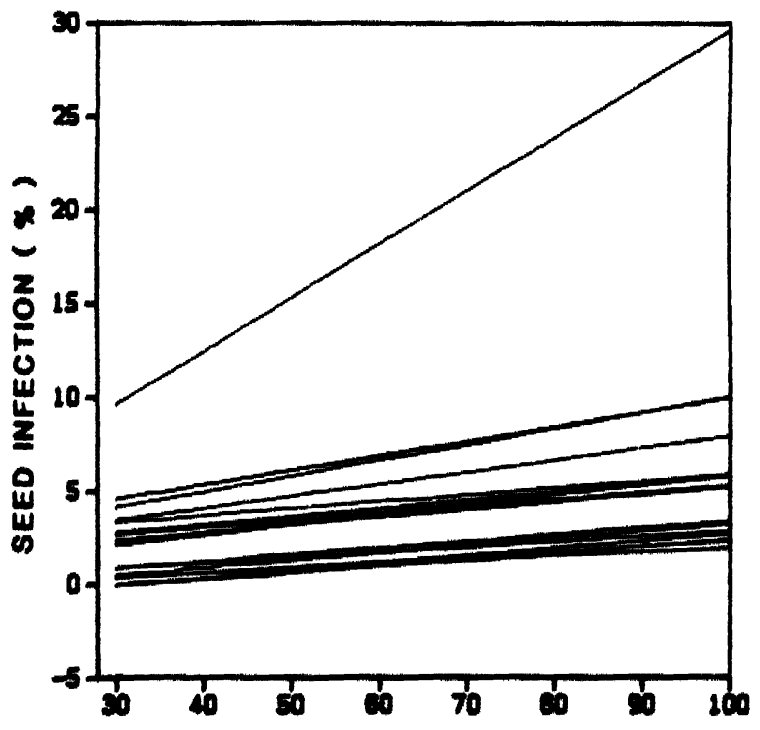

WATER DEFICIT ( $\%)$

Fip. 3. Relationship between water deficit and seed infection by Aspergillus favus in 17 peanut genotypes during the $1985-1986$ postrainy season (All regression lines are significant at $P<0.05$ ). 
significant differences among genotypes for rate of increase in seed infection per unit increase in water deficit. Regrewsion analyses showed vignificant $(P<0.05)$ linear relationship between the levels of water deficit and seed infection by $A$. flavus for all genotypes. Genotypic differences in seed infection by $A$. Navws under high water deficit conditions (bed 10) correlated significantly $(r=0.87$. $P<0.01$ ) with differences under low water deficit condition in both seasons (Fig. 4). In most of the genotypes, the slopes were similar across years. Genotypes differed significantly for seed infection by A. flovus across all leveis of water deficit. TMV 2. Gangapuri, Robut 33-1, Local-3, Sir of Bizapur. GFA Spanish, NG $387,26-5-2$, and $U$ 1-2-1 were susceptible to $A$. flavus. EC $76446(292)$ had the highest levels of seed infection by $A$. flavus (6.0-29.3\%). The genolypes Ah 7223, J II, Exotic-6, U4-47-7, and C55-437 showed low levels of seed infection (0.0-3.3\%) across all levels of water deficit in both weasons.

\section{Discussion}

Drought stress impowed from 85 or 95 days after sowing until harvest substantially increased preharvest seed infection by $A$. flavus. This was confirmed in trials over two postrainy seasons when drought streas during late stages of pod development (95-125 days ufter sowing) gave significant increases in preharvest infection of seeds by $A$. flovus. Similar results have been reported from the United States, where peanuts were drought-stressed in the rainy season using rainout shelters (15).

The linear relationship between water deficit and seed infection by $A$. Javus, shown in the prewent study for all genotypes. demonstrates the reliability of line-source sprinkler irrigation as a screening method: effective enhancement of seed infection being obtained over a considerable range of water deficit (Figs. 2 and 3). This permits a choice to be made of the position on the stress gradient in the field from which to collect material for resistance screening. For instance, in Alfisol fields at ICRISAT Center, seed should be collected from water deficits of $80-99 \%$ since seed infection by $A$. flavus is substantially enhanced at these levels. It is more convenient 10 screen for resistance under drought conditions than under irrigated conditions as seed infection will occur in almost all genotypes. The resistant genotypes had $1.7-3 \%$ seed infection by $A$. Mavus compared with about $30 \%$ in susceptible

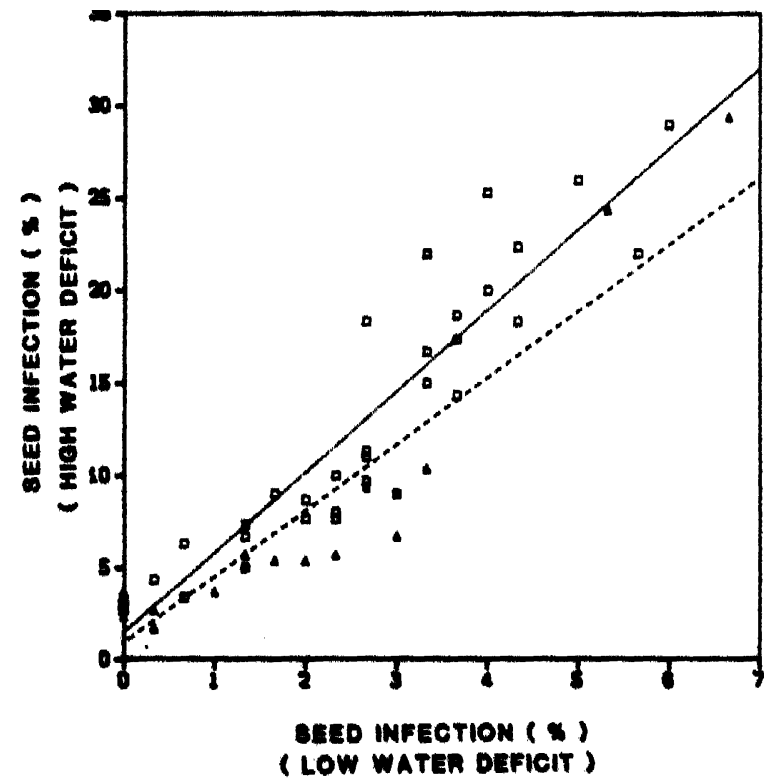

F1. 4. Regrescion lines for reed infection by A spengithes ferves in peanut enotypes in high and low water deficit conditions in the 1983-1984 (-. ) and 1985.1986 (........ ) poetrainy wavons. genotypes under the maximum drought-stress conditions (Fig. 2 and 3). The statistical precision of the trials for seed infection increased with increasing water deficit, and this is well reflected through decreasing coefficients of variation $(30.8-18.0 \%$ in the 1983-1984 season; $32.6-15.5 \%$ in the $1985-1986$ season) as water deficit increased. By imposing late-season drought stress it should be possible to obtain statistical precision in screening for resistance to $A$. flovus from a smaller seed sample than that required when screening under nonstress conditions, a matter of some importance when there is limited seed available in a resistance breeding program.

All genotypes with resistance to in vitro seed colonization by $A$. flavus. except Var. 27 and Faizpur. showed low levels of seed infection by $A$. flavus in the field. Most of the susceptible genotypes had high levels of seed infection, but Exotic- 6 showed resistance to seed infection in the field. Another genotype, U1-2-1, that is highly susceptible to in vitro seed colonization by $A$. flovus had lower levels of seed infection. These results are in accord with the findings of Kisoymbe et al (9) and Mehan et al (12) and emphasize that it should not be assumed that all genotypes resistant to in vitro seed colonization by $A$. flavus are also resistant to seed infection by $A$. flavus in the field. In the case of in vitro seed colonization tests, genotypes can be categorized according to percentage of seeds colonized by $A$. flavus as resistant (up to 15\%). moderately resistant (16-30\%), susceptible (31-50\%), and highly susceptible (over $50 \%$ ) (11). When one deals with natural seed infection in the field. the situation is complicated by the variability of environimental factors influencing seed invasion by $A$. navus, and genotypic variation is best measured by comparison with standard resistant and susceptible control genotypes. In the trials reported in this paper, mean incidence of natural seed infection ranged from zero to $30 \%$. Within this range we considered genotypes with $3 \%$ or lower incidence to be resistant. The genotypic reactions to $\mathrm{A}$. flovus obtained in the present experiments were similar to those found when several of these genotypes were grown in a drought-prone location (Anantapur. Andhra Pradesh, India) in the rainy season (Mehan. unpublished).

Genetic variation in resistance of peanuts to aflatoxin contamination can be evaluated in terms of seed infection by the toxigenic A. Navus as described above. It can accurately be evaluated by comparing the allatoxin contents of seeds of different genotypes. The line-source irrigation system can be used for both purposes in environments where pod-zone soil temperatures are favorable for aflatoxin production. Temperatures between 25 and $31 \mathrm{C}$ are conducive under drought conditions (2). For a specific environment it would be necessary to measure the temperature gradient to enable choice of positions on it most suitable for aflatoxin copntamination.

Although a single drought-stress treatment during pod development (about 30 days before harvest) could be used to improve screening of peanut germ plasm for resistance to seed infection by $A$. Ravus, use of the line-source sprinkJer irrigation method has the advantage that it can be combined with drought tolerance screening. At ICRISAT, physiologists use the linesource irrigation system for initial screening of peanut germ plasm for drought tolerance. This has been taken advantage of to screen the same material for resistance to seed infection by $A$. flovus over a range of water deficits. Such a combined effort may be appropriate in other research institutions concerned with both drought and aflatoxin problems.

\section{LITERATURE CITED}

1. Blaney, B. J. 1985. Mycotoxins in crops grown in differeat climatic repions of Queensiand. Pages 97-108 in: Trichothecenes and Other Mycotoxins. J. Lacey, ed. John Wiky \& Soni Lud.. Chichester, Great Britain.

2. Blankenship. P. D. Cole, R. J., Sanders, T. H.. and Hill. R. A. 1984. Effect of geocarposphere temperature on preharvest colonization of drought-siressed peanuts by Aspengilhus flavis and subsequent allatoxin conturmination. Mycopetholopia 85:69-74.

3. Blankenahip, P. D., Cole, R. J., and Sanders, T. H. 1945. Comparative susceptibility of four experimental peanut lines and the cultivar 
Florunner 10 preharvest aflatoxin contamination. Peanut Sci. $12,70-72$.

4. Davidson. 3. 1. Hill, R. A., Cole, R. J., Mixon, A. C., and Henning. R. J. 1983. Field performance of two peanut cultivars relative to aflatoxin contamination. Peanut Sci. 10:43-47.

5. Dickens. J. W, 1977. Allatoxin occurrence and control during growth. harvest and storage of peanuts. Pages $92-105$ in: Mycotoxins in Human and Animal Health. J. V. Rodricks. C. W. Hesseltine. and M. A. Mehiman. eds. Pathotox Publishers. Inc. II.

6. Dickens, J. W., Satterwhite. J. B., and Sneed, R. E. 1973. Aflatoxincontaminaled peanuts produced on North Carolina Farms in 1968. J. Am. Peanut Res. Educ. Assoc. 5:48-58.

7. Hanks. R. J., Keller, J., Rasmussen, V. P., and Wilson, G. D. 1976. Line source sprinkler for continuous variable irrigation: Crop production studies. Soil Sci. Soc. Am. J. 40:426-429.

8. Hill. R. A. Blankenship. P. D., Cole, R. J., and Sanders, T. H. 198,3. Effects of soil moisture and temperature on preharvest invasion of peanuts by the Aspergillus flavus group and subsequent aflatoxin development. Appl. Environ. Microbiol, 45:628-633.

9. Kisyombe, C. T., Beute. M. K.. and Payne. G. A. 1985. Field evaluation of peanut genotypes for resistance to infection by Aspergillu. parasiticus. Peanut Sci. 12:12-17.
10. Mehan. V. K. 1985. The aflatoxin problem in groundnut -...Approaches to prevention and control. Pages 1-2 in: Proc. of the XXVI Annual AICOR PO Workshop. Nagpur. India.

11. Mehan. V. K.. McDonald. D.. Nigam, S. N., and Lalitha. B. 1981. Groundnut cultivars with seed resistant to invasion by Asperglllus Rovux, Oleagineux 36:501-507.

12. Mehan, V. X.. McDonald, D., Rumakrishna, N., and Williams, J. H. 1986. Effects of genotype and date of harvest on infection of peanut seed by Aspergillus flovus and subsequent contamination with aflatoxin. Peanut Sci. 13:40-50.

13. Petlit, R. E., Taber, R. A., Schroeder, H. W., and Herrison, A. L. 1971. Influence of fungicides and irrigation practice on aflatoxin in peanuts before digging. Appl. Microbiol. 22:629-634.

14. Sanders, T. H., Hill, R. A., Cole, R. J., and Blankenship, P. D. 1981. Effect of droughe on occurrence of Aspergillus flavus in maturing peanuts. J. Am. Oil Chem. Soc. 58:966A-970A.

15. Wilson, D. M., and Stansell, J, R. 1983. Effect of irrigation regimes on aflatoxin contamination of peanut pods. Peanut Sci. 10:54-56.

16. Zambettakis, Ch. Waliyar, F., Bockelee-Morvan, $A_{\text {. }}$ and Pins, $O$ de. 1981. Results of four years of research on resistance of groundnut varieties to Asperzillus flavus. Olengineux 36:377-385. 